\title{
The Role of Red Blood Cell Deformability and Na,K-ATPase Function in Selected Risk Factors of Cardiovascular Diseases in Humans: Focus on Hypertension, Diabetes Mellitus and Hypercholesterolemia
}

\author{
J. RADOSINSKA ${ }^{1,2}$, N. VRBJAR ${ }^{2}$ \\ ${ }^{1}$ Institute of Physiology, Faculty of Medicine, Comenius University in Bratislava, Bratislava, \\ Slovak Republic, ${ }^{2}$ Institute for Heart Research, Slovak Academy of Sciences, Bratislava, Slovak \\ Republic
}

Received June 10, 2016

Accepted June 24, 2016

\begin{abstract}
Summary
Deformability of red blood cells (RBC) is the ability of RBC to change their shape in order to pass through narrow capillaries in circulation. Deterioration in deformability of RBC contributes to alterations in microcirculatory blood flow and delivery of oxygen to tissues. Several factors are responsible for maintenance of RBC deformability. One of them is the Na,K-ATPase known as crucial enzyme in maintenance of intracellular ionic homeostasis affecting thus regulation of cellular volume and consequently RBC deformability. Decreased deformability of RBC has been found to be the marker of adverse outcomes in cardiovascular diseases (CVD) and the presence of cardiovascular risk factors influences rheological properties of the blood. This review summarizes knowledge concerning the RBC deformability in connection with selected risk factors of CVD, including hypertension, hyperlipidemia, and diabetes mellitus, based exclusively on papers from human studies. We attempted to provide an update on important issues regarding the role of $\mathrm{Na}$, K-ATPase in RBC deformability. In patients suffering from hypertension as well as diabetes mellitus the $\mathrm{Na}$, K-ATPase appears to be responsible for the changes leading to alterations in RBC deformability. The triggering factor for changes of RBC deformability during hypercholesterolemia seems to be the increased content of cholesterol in erythrocyte membranes.
\end{abstract}

\section{Key words}

Erythrocyte deformability • Na,K-ATPase - Cardiovascular risk factors

\section{Corresponding author}

N. Vrbjar, Institute for Heart Research, Slovak Academy of Sciences, Dúbravská cesta 9, 84233 Bratislava, Slovak Republic. E-mail: usrdnorb@savba.sk

\section{Introduction}

The biconcave shape of matured human red blood cells (RBC) is an essential property for their physiological function. This shape has two main advantages. Firstly, it allows larger surface area to volume ratio of $\mathrm{RBC}$ that is important for efficient diffusion of respiratory gases. Secondly, RBC is able to undergo deformation. The ability of the RBC to deform is one of the most important determinants of its survival in the circulation, since an average RBC measuring 7.2 micrometers in diameter has to pass through narrow capillaries including as small as 3-4 micrometers in diameter. For effective microcirculatory function and sufficient delivery of oxygen to the tissues RBC deformability is crucial (Schmid-Schonbein 1976). The clinical importance of RBC deformability is even more complex. It is also considered as a major determinant of RBC survival, maintaining the blood in fluid phase even at high hematocrit value and allowing the reduction of blood viscosity in larger vessels (Mokken et al. 1992). Rigidity and deformability of the RBC play very important role in tissue perfusion and in etiology of cardiovascular diseases (CVD) (Fornal et al. 2009, Penco et al. 2000). Decrease in RBC deformability caused by 
genetic abnormalities, age of the cell, aging, hypertension, diabetes mellitus, dyslipidemia or any other factor increases blood viscosity and consequently impairs the proper tissue perfusion. This results in adverse outcomes in CVD (Fornal et al. 2010, Tomaiuolo 2014, Toth et al. 2014). RBC deformability is primarily determined via following three factors: deformability of the RBC membrane itself, intracellular viscosity and the surface area per volume ratio (Tomaiuolo 2014).

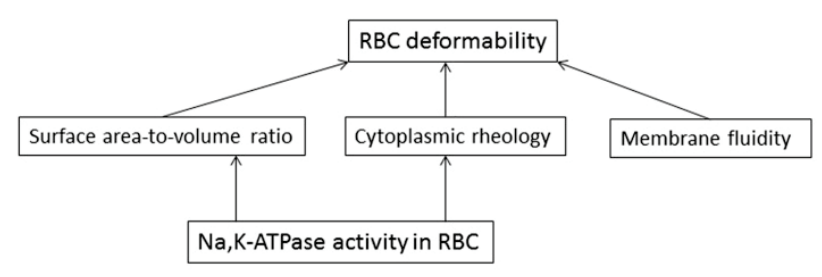

Fig. 1. Schematic presentation of determining factors regulating the RBC deformability in physiological conditions; role of the $\mathrm{Na}$, K-ATPase activity.

Two of above mentioned determinants of RBC deformability are controlled by the activity of $\mathrm{Na}, \mathrm{K}-\mathrm{ATPase}$ in RBC (Fig. 1). Na,K-ATPase maintains the electrochemical gradient across the cell membrane, and in addition to its pump function acts as an essential component of the signal transduction mechanisms in the cells (Elimban et al. 2016). This enzyme is responsible for transport of $\mathrm{Na}^{+}$outside and $\mathrm{K}^{+}$ions inside the cell and resulting volume and water homeostasis. The importance of $\mathrm{Na}, \mathrm{K}-\mathrm{ATPase}$ in $\mathrm{RBC}$ is well visible in patients with stable coronary artery disease, since its activity negatively correlates with the severity of disease (Namazi et al. 2015). Considering these facts the aim of the present review is to provide insight into connection between $\mathrm{Na}, \mathrm{K}$-ATPase activity in $\mathrm{RBC}$ together with RBC deformability and various risk factors of CVD especially hypertension, diabetes mellitus and hyperlipidemia, based exclusively on papers from human studies.

\section{Hypertension}

Several studies of patients suffering from essential hypertension showed decreased deformability of RBC. It has been shown that deformability of RBC was impaired in patients with hypertension even under the treatment and that this impairment was inversely proportional to the mean arterial blood pressure (Odashiro et al. 2015). Decreased RBC deformability in hypertensives was accompanied with altered maintenance of intracellular homeostasis of calcium (David-Dufilho et al. 1992, Cicco et al. 2001) and sodium ions (Kazennov et al. 1990). As compared to normotensives, the patients with borderline hypertension displayed significantly lower activity of erythrocyte Na,K-ATPase, which indicated a hypothesis that in the blood of hypertensive subjects an enzyme inhibitor of erythrocyte Na,K-ATPase may circulate (Kazennov et al. 1987). Investigations of regulatory mechanisms of membrane functions in hypertension by means of electron spin resonance and spin labeling methods documented the relationship between endogenous $\mathrm{Na}, \mathrm{K}$-ATPase inhibitor (digitalislike factor; DLF) and erythrocyte membrane fluidity in essential hypertension. The level of plasma DLF content was higher in hypertensive patients than in normotensive subjects and correlated with the decrease of erythrocyte membrane fluidity (Tsuda et al. 1992). Inhibition of the Na-K pump by digoxin in vitro correlates with reduced RBC deformability. However, this effect occurred at toxic doses of digoxin only. During in vivo testing the intake of digoxin ( $0.2 \mathrm{mg}$ b.i.d.) in nine healthy volunteers, over a 5-day period did not alter the deformability of RBC and Na,K-ATPase activity (Wambach et al. 1985). The hypothesis that endogenous DLF might participate in essential hypertension led Devynck et al. (1987) to investigate the presence of plasma compounds interacting with digoxin antibodies. They observed positive correlations between systolic and diastolic blood pressure and apparent digoxin-like immunoreactivity of the plasma in man.

It was shown, that the higher intracellular concentration of sodium is in RBC, the higher is the blood pressure level. These intracellular sodium concentration changes that were accompanied with lowering the Na-pump activity, were more prominent in men than in women and in people whose both parents were hypertensive compared to those with only one parent being hypertensive (Zhao et al. 1984). In addition, comparison of normotensives with an average blood pressure $127 / 80 \mathrm{~mm} \mathrm{Hg}$ and hypertensives with an average blood pressure 147/94 mm Hg (aged 23-27 years) resulted in decrease of RBC deformability in hypertensive subjects which was not accompanied by inhibition of the Na,K-ATPase (Hossmann et al. 1986). So the interrelationship between the DLF, Na,K-ATPase activity and deformability of RBC needs further clarification.

Beside the effect of endogenous DLF, another factor influencing the $\mathrm{Na}, \mathrm{K}$-ATPase activity and $\mathrm{RBC}$ 
deformability has been hypothesized. The shape of RBC and consequent adaptability of human erythrocyte plasma membrane is determined by cytoskeleton underlying the membrane and connecting it to various localities in the intracellular space. The presence of various isoforms of tubulin was confirmed by proteomic studies in human RBC (Goodman et al. 2007). Later it was shown that tubulin in human RBC is distributed in three fractions: membrane bound, sedimentable and soluble compartments. In RBC from hypertensive patients membrane tubulin fraction was increased by approximately $150 \%$, what resulted in inhibition of $\mathrm{Na}, \mathrm{K}-\mathrm{ATP}$ ase activity (Amaiden et al. 2011). Alongside with localization of tubulin in the cell, its chemical modification plays also important role in regulation of Na,K-ATPase and RBC deformability. Very important seems to be the detyrosination/tyrosination cycle of tubulin. In hypertensive patients the level of detyrosinated tubulin was higher in the sedimentable fraction. Consequent translocation of detyrosinated tubulin to the plasma membrane enhanced the inhibitory effect of tubulin on $\mathrm{Na}, \mathrm{K}$-ATPase activity resulting in reduced RBC deformability (Amaiden et al. 2015).

As a further factor influencing the functionality of $\mathrm{RBC}$, the nitric oxide (NO) was identified. Based on the finding, that $\mathrm{RBC}$ contains functional NO synthase it was proposed that RBC synthesize and use NO to modulate its own physiology (Jubelin and Gierman 1996). Later it was shown that NO produced either in $\mathrm{RBC}$ or in endothelial cells increased the membrane fluidity and decreased the rigidity of cell membranes (Bor-Kucukatay et al. 2003). Furthermore, the greater effect of $\mathrm{NO}$ on the membrane fluidity of RBC in samples from hypertensive patients compared with normotensive subjects indicated that NO might actively participate in the regulation of rheological behavior of $\mathrm{RBC}$ and may have a crucial role in the improvement of microcirculation in hypertension (Tsuda et al. 2000). The lower deformability of RBC from hypertensive patients was accompanied with higher production of NO after acetylcholine stimulation as compared with $\mathrm{RBC}$ from healthy persons (Carvalho et al. 2006). Nevertheless, for complete information it should be added that excess of NO produced by leucocytes decreases the deformability of RBC (Korbut and Gryglewski 1993), so the NO concentration is of critical importance in this modulatory mechanism (Bor-Kucukatay et al. 2003).

Since oxidative stress plays a role in the pathophysiology of essential hypertension and $\mathrm{Na}, \mathrm{K}-\mathrm{ATPase}$ is modulated by the surrounding lipid microenvironment, lipid peroxidation may alter the interactions of this enzyme with the membrane components. Reduction of Na,K-ATPase activity and elevation of the thiobarbituric acid reactive substances may underlie the pathophysiological aspects linked to the prehypertensive status (Malfatti et al. 2012). Treated patients suffering from essential hypertension showed decreased oxidative stress and increased fluidity of RBC membrane, together with higher activity of erythrocyte Na,K-ATPase after supplementation with vitamins $\mathrm{C}+\mathrm{E}$ (Rodrigo et al. 2014).

However, there were published also controversial data concerning the mechanical properties of RBC membranes in hypertensive patients. On the one side, a decrease in membrane fluidity was documented in hypertensive patients (Tsuda et al. 2000, 2011). The observation that lower membrane fluidity of erythrocytes was associated with higher plasma insulin level in hypertensive patients seems to be interesting (Tsuda et al. 2001). Membrane abnormality of RBC was attenuated with low salt intake, and, on the contrary, was more prominent with high-salt intake in essential hypertension (Masuyama et al. 1988). On the other side, no changes were observed in Na,K-ATPase activity and fluidity of RBC membranes (Pytel et al. 2012).

The importance of RBC deformability determination in patients suffering from essential hypertension was documented by correlation between this parameter and the levels of soluble vascular adhesion molecules-1 as well as soluble intracellular adhesion molecules-1 in circulation. Therefore, deformability of RBC may serve as a marker of endothelial dysfunction at least in hypertensives (Fornal et al. 2011).

\section{Diabetes mellitus}

Concerning the diabetes mellitus (DM), it is known for more than forty years that this disease is accompanied with impaired microcirculation resulting in relative tissue hypoxia (Ditzel and Standl 1975, Ditzel et al. 1978). In this impairment the worsened penetration of $\mathrm{RBC}$ into target tissues is involved (Le Devehat et al. 1994). DM induces numerous abnormalities of RBC including increased aggregation (Schmid-Schonbein and Volger 1976), increased membrane viscosity (Baba et al. 1979) and decreased deformability (McMillan 1975, Vague and Juhan 1983). Reduced viscoelastic properties of erythrocyte membranes have been attributed to the alterations in membrane lipid-protein interactions together with the increased glycosylation-derived internal 
viscosity in juvenile DM (Watala et al. 1992). A scanning electron microscopy and atomic force microscopy have shown significant changes in membrane structure of RBC in type II DM (Buys et al. 2013). Another reason for decreased deformability of RBC in DM was ascribed to lower activity of the Na,K-ATPase leading to accumulation of intracellular sodium ions, with subsequent increase of free calcium ions in $\mathrm{RBC}$ due to competition in transmembrane exchange (Gardner and Bennett 1986, Juhan-Vague et al. 1986). The incubation of human RBC with glucose in higher concentration significantly lowered the Na,K-ATPase activity and increased the lipid peroxidation and protein glycosylation of RBC membranes compared with normal glucosetreated RBC (Jain and Lim 2000). The restoration of normoglycemia by insulin treatment in subjects with uncontrolled insulin dependent DM resulted in normalization of Na,K-ATPase activity, as well as the deformability of RBC after $24 \mathrm{~h}$ (Juhan-Vague et al. 1986). This result shows the importance to check the degree of glycemia control when studying rheological parameters in DM. The improvement of Na,K-ATPase activity in erythrocyte membrane was also observed after 24 weeks of metformin administration in type II diabetic patients (Chakraborty et al. 2011). The addition of pioglitazone, but not glimepiride, to metformin resulted in improvement of RBC deformability beyond improving blood glucose control in type II diabetic patients which was associated with an increase in plasma adiponectin levels (Forst et al. 2010). The similar situation was also observed in hypertensive men whose plasma adiponectin levels were lower than in normotensive men. The above mentioned hypoadiponectinemia was associated with decreased membrane fluidity of erythrocytes at least partially by the NO-dependent mechanism, since the plasma adiponectin levels were correlated with plasma NO metabolites (Tsuda 2006).

For longer time it was believed that the connecting peptide, so called C-peptide bridging the insulin $\mathrm{A}$ and $\mathrm{B}$ chains in the precursor proinsulin molecule is just a byproduct of insulin synthesis. Initial studies oriented to discovery of potential physiological role of proinsulin C-peptide brought negative results (Kitabchi 1970, Hoogwerf et al. 1986). However, later comparison of Na,K-ATPase activity in RBC from patients with type I DM, with patients suffering from type II DM and control subjects revealed that the mean enzyme activity was lower in the type I diabetic patients by $28 \%$ as compared with control subjects. In type II diabetic patients, stepwise regression analysis showed that fasting C-peptide level was the only factor independently correlating with Na,K-ATPase activity (De La Tour et al. 1998). In addition, patients with type II DM with good residual C-peptide secretion were protected better from endothelial dysfunction that those with low C-peptide secretion (Manzella et al. 2003). These results indicated a potential role of C-peptide in regulating the Na,K-ATPase in RBC. Another investigation showed that in vitro preincubation of the blood samples from type I diabetic patients with human proinsulin C-peptide for $8 \mathrm{~h}$ restored the deformability of $\mathrm{RBC}$, almost to values of samples from control subjects. In samples from control subjects, the preincubation with C-peptide did not modify the deformability of RBC. It was concluded that C-peptide is able to ameliorate the impaired deformability of RBC in patients suffering from type I DM and it was hypothesized that this effect is mediated by restoration of Na,K-ATPase activity, which is known to be attenuated in diabetic patients (Kunt et al. 1999). This hypothesis was confirmed by study of type I diabetic patients, in which C-peptide supplementation increased the erythrocyte Na,K-ATPase activity by about $100 \%$. There was found a linear relationship between plasma C-peptide levels and erythrocyte Na,K-ATPase activity. Using laserdiffractoscopic method a significant improvement of RBC deformability was observed after C-peptide administration in $\mathrm{RBC}$ of type I diabetic patients. Inhibition of the $\mathrm{Na}, \mathrm{K}-\mathrm{ATPase}$ by its specific inhibitor ouabain completely abolished the effect of C-peptide on RBC deformability (Forst and Kunt 2004). Further study was oriented to a question which part of the C-peptide consisting of 31 amino-acids is responsible for regulation of the Na,K-ATPase activity and consequent deformability of RBC. Incubation of blood samples from patients with type I DM and healthy controls with human C-peptide, C-terminal hexapeptide, C-terminal pentapeptide resulted in improvement of RBC deformability. This improvement was dependent on activation of $\mathrm{Na}, \mathrm{K}-\mathrm{ATPase}$, as the presence of ouabain abolished the above effect. Incubation of $\mathrm{RBC}$ with the middle fragment comprising residues 11-19 of C-peptide did not show detectable effect, suggesting that the $\mathrm{C}$-terminal residues of C-peptide are causally involved in this effect (Hach et al. 2008).

The lowered activity of Na,K-ATPase in RBC and consequent decrease of RBC deformability may also originate in polymorphism of the ATP1A1 gene which is encoding the $\alpha-1$ isoform of the enzyme predominant in RBC. It was documented that polymorphism in the intron 1 of this gene is associated with lower enzyme activity in patients with C-peptide deficiency either with type I or type II DM, but not in normal individuals 
(Vague et al. 1997, Jannot et al. 2002).

Beside the mechanism of polymorphism of the gene responsible for synthesis of $\alpha-1$ isoform of the $\mathrm{Na}, \mathrm{K}$-ATPase and insufficiency of C-peptide further possible mechanism of the $\mathrm{Na}, \mathrm{K}-\mathrm{ATPase}$ regulation in DM was identified. Studies on RBC from diabetic patients resulted in lowering of Na,K-ATPase activity by $50 \%$ alongside with increased membrane-associated tubulin content by more than $200 \%$ as compared with normal subjects. It was proposed that increased glucose concentration in blood triggers tubulin-induced effects leading to microtubule formation and consequent $\mathrm{Na}, \mathrm{K}-\mathrm{ATP}$ ase inhibition (Rivelli et al. 2012). Recently it was shown that high concentrations of glucose promote tubulin acetylation and translocation of this tubulin to the membrane, thus reducing deformability of RBC (Nigra et al. 2016).

\section{Hypercholesterolemia}

Another widely spread risk factor of CVD is hypercholesterolemia. Excess of plasma cholesterol level induces changes in basic properties of human erythrocyte plasma membrane, including its fluidity and the intensity of lipid peroxidation (Koter et al. 2002, 2003, Broncel et al. 2007). Increase of membrane cholesterol caused a progressive decrease in deformability of $\mathrm{RBC}$, as measured by filtration (Cooper et al. 1975). Studies oriented to the influence of high cholesterol level in serum and in the LDL fraction showed significantly lower deformability of $\mathrm{RBC}$ in the group of hypercholesterolemic patients as compared with age-matched normocholesterolemic subjects (Kohno et al. 1997). A significant negative correlation between low-density lipoprotein (LDL) cholesterol level and $\mathrm{Na}, \mathrm{K}-\mathrm{ATPase}$ activity in RBC was also noticed in type II diabetic patients (Chakraborty et al. 2011). Hypercholesterolemic type II diabetic patients had significantly lower deformability of RBC compared with normocholesterolemic type II diabetic patients. These data suggest that elevated plasma cholesterol may impair RBC deformability by an additional effect to hyperglycemia in type II diabetic patients (Ercan et al. 2002). The filterability of RBC was significantly proportional to the HDL-cholesterol values, whereas it was inversely proportional to the triglyceride levels in apparently healthy subjects (Ejima et al. 2000).

One year lasting therapy of hypercholesterolemic patients with pravastatin, an inhibitor of hepatic hydroxymethyl glutaryl coenzyme A
(HMG-CoA) reductase, reduced the serum cholesterol level by $23 \%$ alongside with significant improvement of RBC deformability by approximately $20 \%$. Furthermore, significant relation between the improvement of $\mathrm{RBC}$ deformability and the reduction of serum cholesterol or LDL cholesterol were observed. The results suggested that RBC deformability was reduced in hypercholesterolemic patients, and that long-term cholesterol-lowering therapy could improve reduced RBC deformability, which may contribute to the improvement microcirculation and organ perfusion (Kohno et al. 1997). The administration of another HMG-CoA reductase inhibitor - atorvastatin (10 mg/day) improved $\mathrm{RBC}$ deformability after 1 month and 3 months of treatment except the lipid lowering effect (Szapary et al. 2004). Atorvastatin at $10 \mathrm{mg} /$ day dose and simvastatin at $40 \mathrm{mg} /$ day in a similar degree significantly increased the lowered activity of Na,K-ATPase in hyperlipidemic patients. However, simvastatin decreased stronger the membrane cholesterol content in $\mathrm{RBC}$ and erythrocyte membrane fluidity than atorvastatin (Broncel et al. 2007).

Unfortunately, filtration-based studies do not provide a direct measure of the viscoelastic constants, but their output is based on some parameters that are indirectly related to $\mathrm{RBC}$ deformability. The other approach - micropipette technique used to assess cell deformability tests the intrinsic viscoelastic properties of the membrane, but it is insensitive to the cell geometry and shape. Thus, different techniques may have different sensitivities to various factors involved in resulting deformability of RBC especially in condition of hypercholesterolemia (Chabanel et al. 1983, Tomaiuolo 2014). This may be possible explanation of controversial data concerning the deformability of $\mathrm{RBC}$ in hypercholesterolemic patients. The above mentioned lower deformability of RBC in hypercholesterolemia is in contrast to studies showing this parameter unchanged (Chabanel et al. 1983, Vaya et al. 1998).

Familiar type-2 hypercholesterolemia is autosomal dominantly inherited deficiency of the expression LDL receptor on the cell surfaces leading to excess of plasma LDL cholesterol and LDL deposition in the cells. The erythrocyte membranes of children affected by type-2 hypercholesterolemia revealed higher erythrocyte membrane cholesterol/phospholipid ratio than those of normolipemic individuals (Martinez et al. 1998). In adult patients suffering from type 2 hypercholesterolemia, beside the changes in the structure and fluidity of erythrocyte membranes, impaired function and structure of plasma membrane proteins, was observed. It 
was documented by decreased concentration of thiol groups in membrane proteins followed by lower activity of Na,K-ATPase (Koter et al. 2004). Generally, a decrease in the accessible thiol groups correlates with increased aggregation of membrane proteins since a significant fraction of oxidized groups that can be involved in the formation of disulfide bridges (Soszynski and Bartosz 1997). Thus, free radical formation coexisting with hypercholesterolemia may lead to lipid peroxidation and result in modification of membrane proteins including Na,K-ATPase. The patients affected by type 2 hyperlipidemia that were not given medications known to affect lipid levels or interact with statins, and with body mass index (BMI) lower than 35, were given $10 \mathrm{mg}$ of atorvastatin per day. The lowered erythrocyte membrane fluidity was significantly higher after 4 weeks and remained on the same level after 12 weeks of the atorvastatin therapy (Koter et al. 2002). Beside the statin therapy, the deformability of RBC was also improved in hyperlipidemic patients treated with fenofibrate ( $250 \mathrm{mg} /$ day) for 8 weeks (Saklamaz et al. 2005).

Concerning the relationship between the erythrocyte membrane fluidity and the activity of $\mathrm{Na}, \mathrm{K}-\mathrm{ATPase}$ in $\mathrm{RBC}$, interesting seems to be the observation that group of hypercholestrolemic patients with lowered enzyme activity and membrane fluidity of RBC after 2-month lasting supplementation of polyphenolic extract from Aronia melanocarpa showed significant decrease of erythrocyte cholesterol concentration (by $26 \%$ ) and a decrease of lipid peroxidation (by $40 \%$ ), and an increase of membrane fluidity. However, the membrane fluidity of RBC did not reach the values found in the control group despite the 2-month therapy and the activity of the Na,K-ATPase remained unchanged (Duchnowicz et al. 2012). So, it may be anticipated that in hypercholesterolemic patients the higher content of cholesterol and the state of oxidation of lipids directly in membranes plays primary role in regulating the deformability of RBC. It is in concordance with results of another study performed in patients diagnosed with coronary artery disease. It showed an increase in the level of lipid peroxidation (by $13 \%$ ) and total cholesterol (by $19 \%$ ), and a decrease in membrane fluidity (by $14 \%$ ) in the subsurface layers and in the deeper layers of erythrocyte membrane (by $7 \%$ ) isolated from patients with coronary artery disease in comparison to healthy controls. A significant decrease in catalase (by $10 \%$ ) and superoxide dismutase (by $17 \%$ ) activities were also observed. So, disorders in the antioxidant system were accompanied with changes in the membrane structure of RBC (Pytel et al. 2013). The NO levels achieved on RBC of hypercholesterolemic patients were higher against the NO levels for the control group. Moreover, besides the lower deformability of $\mathrm{RBC}$ obtained from hypercholesterolemic patients, the RBC produced higher NO levels after acetylcholine stimulation than RBC obtained from blood samples of healthy subjects (Carvalho et al. 2006).

LDL immunoadsorption apheresis is considered for appropriate LDL lowering when maximal drug therapy fails to achieve adequate LDL cholesterol reduction. Single LDL apheresis resulted in significant reduction of plasma viscosity, whole blood viscosity and erythrocyte aggregation index. However, long-term apheresis had no sustained effect on plasma and whole blood viscosity in hypercholesterolemic patients with coronary artery disease (Pusl et al. 2009). The patients with coronary artery disease and severe LDL hypercholesterolemia regularly treated with LDL apheresis were subjected to advanced direct adsorption of lipoproteins apheresis resulting in reduction of LDL cholesterol and improvement of various hemorheological parameters including RBC deformability (Otto et al. 2002).

\section{Some other cardiovascular risk factors}

Rheological blood behavior is influenced also by aging itself. The age-related decrease of RBC deformability appears to be due to the cumulative effect of various intra- and extra-cellular factors as age-related oxidative stress (Goi et al. 2005), altered sialic acid content (Huang et al. 2011) and Na,K-ATPase activity of the cell membrane (Maurya and Prakash 2013).

Obesity is known to be associated with elevated risk for CVD. Concerning the relationship of $\mathrm{Na}, \mathrm{K}-\mathrm{ATPase}$ activity and physical properties of RBC membranes various data were published. The increase of erythrocyte viscosity was present even in the absence of impaired glucose tolerance, diabetes, hypertension or hyperlipidemia (Rillaerts et al. 1989). The increased $\mathrm{Na}, \mathrm{K}-\mathrm{ATPase}$ activity was demonstrated in the RBC membranes of obese, normotensive, non-diabetic subjects together with decreased membrane fluidity, which become apparent without detectable changes in plasma lipids (Faloia et al. 1999). The long-term hypocaloric feeding lowered altered erythrocyte Na,K-ATPase in obese individuals (Pasquali et al. 1988). On the other hand results of another study support the hypothesis that abnormalities in the erythrocyte Na,K-ATPase system are not usual in the obese population but are probably present 
only in a limited number of selected patients (Pasquali et al. 1985). However, measurement of erythrocyte deformability by ektacytometric techniques showed no significant difference between obese patients without other cardiovascular risk factors and controls (Sola et al. 2007).

The metabolic syndrome (MS) was identified as a multiplex risk factor for CVD which is one of the major causes of death. Overweight or obesity, abnormal lipid metabolism, hypertension, and insulin resistance are the major contributors in MS. The MS is believed to be a consequence of a sedentary lifestyle, excessive intake of calories and physical inactivity, although genetic factors are also involved. The membrane fluidity was lower in $\mathrm{RBC}$ from patients with MS than in the ones from control group. These alterations in RBC of patients with MS were ascribed to higher concentration of cholesterol in the membrane and an increased oxidative stress (Ziobro et al. 2013).

Changes in hemorheological parameters after ingestion of ethanol were studied in patients with ischemic cerebrovascular disease and elderly healthy men. The ingestion of $1 \mathrm{~g} / \mathrm{kg}$, but not $0.5 \mathrm{~g} / \mathrm{kg}$ of ethanol resulted in impairment of $\mathrm{RBC}$ deformability in patients with ischemic cerebrovascular disease, while hemorheology was not significantly changed in healthy men (Nagai et al. 2001). The chronic alcohol consumption resulted in significant decrease of $\mathrm{Na}, \mathrm{K}-\mathrm{ATPase}$ activity in $\mathrm{RBC}$ and higher rigidity of erythrocyte membranes (Maturu et al. 2010).

Study of chronic cigarette smokers showed increased erythrocyte membrane lipid peroxidation and rigidity with decreased $\mathrm{Na}, \mathrm{K}$-ATPase activity and thiol groups in male volunteers smoking for 7-10 years at least $12 \pm 2$ cigarettes per day (Padmavathi et al. 2010).

According to official statistical data there is a significant difference between pre-menopausal women and age-matched men in morbidity and mortality from CVD. Compared to female blood, male blood had higher viscosity and $\mathrm{RBC}$ aggregation and lower RBC deformability (Kameneva et al. 1999). The hormone (estrogen) replacement therapy significantly increased the membrane fluidity of RBC with a concomitant increase in plasma NO metabolite level in postmenopausal women (Tsuda et al. 2003).

\section{Conclusion}

Data presented in this review allow us to suggest that the interrelationship between the deformability of RBC and $\mathrm{Na}, \mathrm{K}$-ATPase function varies depending on the nature of cardiovascular risk factors. In patients suffering from hypertension as well as diabetes mellitus Na,K-ATPase appears to be mostly responsible for the changes leading to alterations in RBC deformability (Fig. 2). Changes of RBC deformability were commonly accompanied by changes in $\mathrm{Na}, \mathrm{K}$-ATPase activities.

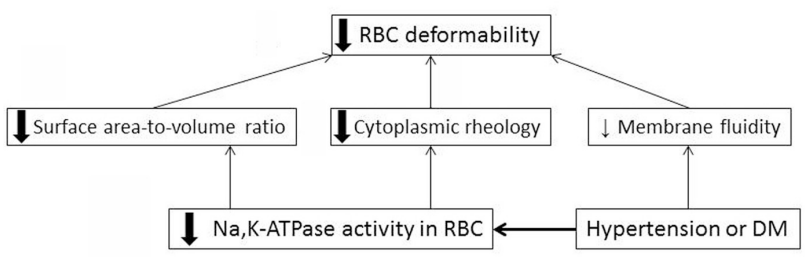

Fig. 2. Schematic presentation of determining factors regulating the RBC deformability in hypertension and diabetes mellitus; deterioration of $\mathrm{Na}, \mathrm{K}-\mathrm{ATPa} e$ the most probably precedes decrease in RBC deformability.

The triggering factor for changes of $\mathrm{RBC}$ deformability during hypercholesterolemia seems to be the increased content of cholesterol in erythrocyte membranes resulting in decrease of membrane fluidity (Fig. 3). The decrease of membrane cholesterol resulted in improvement of hemorheological parameters including RBC deformability despite the unchanged Na,K-ATPase activity.

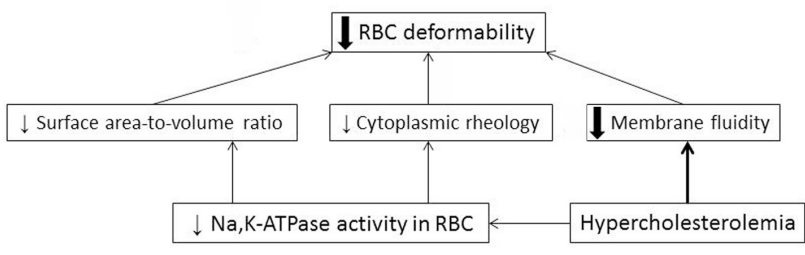

Fig. 3. Schematic presentation of determining factors regulating the RBC deformability in hypercholesterolemia; increase of membrane cholesterol caused a progressive decrease in membrane fluidity and consequently deterioration of RBC deformability.

In respect of treatment of CVD it could be challenging to determine possible effects of different interventions in CVD on $\mathrm{Na}, \mathrm{K}-\mathrm{ATPase}$ activity and consequent $\mathrm{RBC}$ deformability. Those approaches that result in improvement of microcirculation should be preferred. In respect of prevention of CVD any activity leading to improvement of $\mathrm{Na}, \mathrm{K}$-ATPase activity in $\mathrm{RBC}$ and consequent $\mathrm{RBC}$ deformability may be considered as simultaneous prevention of CVD. 


\section{Conflict of Interest}

There is no conflict of interest.

\section{Acknowledgements}

This study was supported by grants VEGA SR no. $2 / 0141 / 13,1 / 0032 / 14$.

\section{References}

AMAIDEN MR, SANTANDER VS, MONESTEROLO NE, CAMPETELLI AN, RIVELLI JF, PREVITALI G, ARCE CA, CASALE CH: Tubulin pools in human erythrocytes: altered distribution in hypertensive patients affects $\mathrm{Na}^{+}, \mathrm{K}^{+}$-ATPase activity. Cell Mol Life Sci 68: 1755-1768, 2011.

AMAIDEN MR, SANTANDER VS, MONESTEROLO NE, NIGRA AD, RIVELLI JF, CAMPETELLI AN, PIE J, CASALE CH: Effects of detyrosinated tubulin on $\mathrm{Na}^{+}, \mathrm{K}^{+}$-ATPase activity and erythrocyte function in hypertensive subjects. FEBS Lett 589: 364-373, 2015.

BABA Y, KAI M, KAMADA T, SETOYAMA S, OTSUJI S: Higher levels of erythrocyte membrane microviscosity in diabetes. Diabetes 28: 1138-1140, 1979.

BOR-KUCUKATAY M, WENBY RB, MEISELMAN HJ, BASKURT OK: Effects of nitric oxide on red blood cell deformability. Am J Physiol Heart Circ Physiol 284: H1577-H1584, 2003.

BRONCEL M, BAŁA A, KOTER-MICHALAK M, DUCHNOWICZ P, WOJSZNIS W, CHOJNOWSKAJEZIERSKA J: Physicochemical modifications induced by statins therapy on human erythrocytes membranes. Wiad Lek 60: 321-328, 2007.

BUYS AV, VAN ROOY MJ, SOMA P, VAN PAPENDORP D, LIPINSKI B, PRETORIUS E: Changes in red blood cell membrane structure in type 2 diabetes: a scanning electron and atomic force microscopy study. Cardiovasc Diabetol 12: 25, 2013.

CARVALHO FA, MARIA AV, BRAZ NOGUEIRA JM, GUERRA J, MARTINS-SILVA J, SALDANHA C: The relation between the erythrocyte nitric oxide and hemorheological parameters. Clin Hemorheol Microcirc 35: 341-347, 2006.

CHABANEL A, FLAMM M, SUNG KLP, LEE MM, SCHACHTER D, CHIEN S: Influence of cholesterol content on red cell membrane viscoelasticity and fluidity. Biophys $J$ 44: 171-176, 1983.

CHAKRABORTY A, CHOWDHURY S, BHATTACHARYYA M: Effect of metformin on oxidative stress, nitrosative stress and inflammatory biomarkers in type 2 diabetes patients. Diabetes Res Clin Pract 93: 56-62, 2011.

CICCO G, CARBONARA MC, STINGI GD, PIRRELLI A: Cytosolic calcium and hemorheological patterns during arterial hypertension. Clin Hemorheol Microcirc 24: 25-31, 2001.

COOPER RA, ARNER EC, WILEY JS, SHATTIL SJ: Modification of red cell membrane structure by cholesterol-rich lipid dispersions. A model for the primary spur cell defect. J Clin Invest 55: 115-126, 1975.

DAVID-DUFILHO M, ASTARIE C, PERNOLLET MG, DEL PINO M, LEVENSON J, SIMON A, DEVYNCK MA: Control of the erythrocyte free $\mathrm{Ca}^{2+}$ concentration in essential hypertension. Hypertension 19: 167-174, 1992.

DE LA TOUR DD, RACCAH D, JANNOT MF, COSTE T, ROUGERIE C, VAGUE P: Erythrocyte Na/K ATPase activity and diabetes: relationship with C-peptide level. Diabetologia 41: 1080-1084, 1998.

DEVYNCK MA, PERNOLLET MG, MEYER P: Endogenous digitalis-like compounds in essential and experimental hypertension. Int J Rad Appl Instrum B 14: 341-352, 1987.

DITZEL J, STANDL E: The problem of tissue oxygenation in diabetes mellitus. Acta Med Scand Suppl 578: 59-68, 1975.

DITZEL J, JAEGER P, STANDL E: An adverse effect of insulin on the oxygen-release capacity of red blood cells in nonacidotic diabetics. Metabolism 27: 927-934, 1978.

DUCHNOWICZ P, NOWICKA A, KOTER-MICHALAK M, BRONCEL M: In vivo influence of extract from Aronia melanocarpa on the erythrocyte membranes in patients with hypercholesterolemia. Med Sci Monit 18: CR569CR574, 2012.

EJIMA J, IJICHI T, OHNISHI Y, MARUYAMA T, KAJI Y, KANAYA S, FUJINO T, UYESAKA N, OHMURA T: Relationship of high-density lipoprotein cholesterol and red blood cell filterability: cross-sectional study of healthy subjects. Clin Hemorheol Microcirc 22: 1-7, 2000. 
ELIMBAN V, BARTEKOVA M, XU YJ, DHALLA NS: Regulation of membrane Na+-K+ ATPase in health and disease. In: Advances in Biochemistry in Health and Disease. S CHAKRABORTI, NS DHALLA (eds), Springer, New York, 2016, vol 15, pp 311-322.

ERCAN M, KONUKOGLU D, ERDEM T, ONEN S: The effects of cholesterol levels on hemorheological parameters in diabetic patients. Clin Hemorheol Microcirc 26: 257-263, 2002.

FALOIA E, GARRAPA GG, MARTARELLI D, CAMILLONI MA, LUCARELLI G, STAFFOLANI R, MANTERO F, CURATOLA G, MAZZANTI L: Physicochemical and functional modifications induced by obesity on human erythrocyte membranes. Eur J Clin Invest 29: 432-437, 1999.

FORNAL M, KORBUT RA, KROLCZYK J, GRODZICKI T: Left ventricular geometry and rheological properties of erythrocytes in patients at cardiovascular disease risk. Clin Hemorheol Microcirc 43: 203-208, 2009.

FORNAL M, KORBUT RA, KROLCZYK J, GRODZICKI T: Evolution of rheological properties of erythrocytes and left ventricular geometry in cardiovascular disease risk patients. Clin Hemorheol Microcirc 45: 155-159, 2010.

FORNAL M, KORBUT RA, GRODZICKI T: Relevance of erythrocyte deformability to the concentration of soluble cell adhesion molecules and glomerular filtration rate in patients with untreated essential hypertension. Clin Hemorheol Microcirc 49: 323-329, 2011.

FORST T, KUNT T: Effects of C-peptide on microvascular blood flow and blood hemorheology. Exp Diabesity Res 5 : 51-64, 2004.

FORST T, WEBER MM, LOBIG M, LEHMANN U, MULLER J, HOHBERG C, FRIEDRICH C, FUCHS W, PFUTZNER A: Pioglitazone in addition to metformin improves erythrocyte deformability in patients with Type 2 diabetes mellitus. Clin Sci (Lond) 119: 345-351, 2010.

GARDNER K, BENNETT V: A new erythrocyte membrane associated protein with calmodulin binding activity. Identification and purification. J Biol Chem 261: 1339-1348, 1986.

GOI G, CAZZOLA R, TRINGALI C, MASSACCESI L, VOLPE SR, RONDANELLI M, FERRARI E, HERRERA CJ, CESTARO B, LOMBARDO A, VENERANDO B: Erythrocyte membrane alterations during ageing affect beta-D-glucuronidase and neutral sialidase in elderly healthy subjects. Exp Gerontol 40: 219-225, 2005.

GOODMAN SR, KURDIA A, AMMANN L, KAKHNIASHVILI D, DAESCU O: The human red blood cell proteome and interactome. Exp Biol Med (Maywood) 232: 1391-1408, 2007.

HACH T, FORST T, KUNT T, EKBERG K, PFUTZNER A, WAHREN J: C-peptide and its C-terminal fragments improve erythrocyte deformability in type 1 diabetes patients. Exp Diabetes Res 2008: 730594, 2008.

HOOGWERF BJ, BANTLE JP, GAENSLEN HE, GREENBERG BZ, SENSKE BJ, FRANCIS R, GOETZ FC: Infusion of synthetic human C-peptide does not affect plasma glucose, serum insulin, or plasma glucagon in healthy subjects. Metabolism 35: 122-125, 1986.

HOSSMANN V, BONNER G, WAMBACH G, LAASER U, KAUFMANN W: Blood viscosity: a pathogenetic factor in the development of essential hypertension? Clin Exp Hypertens A 8: 673-680, 1986.

HUANG YX, WU ZJ, MEHRISHI J, HUANG BT, CHEN XY, ZHENG XJ, LIU WJ, LUO M: Human red blood cell aging: correlative changes in surface charge and cell properties. J Cell Mol Med 15: 2634-2642, 2011.

JAIN SK, LIM G: Lipoic acid decreases lipid peroxidation and protein glycosylation and increases $(\mathrm{Na}(+)+\mathrm{K}(+))$ - and $\mathrm{Ca}(++)$-ATPase activities in high glucose-treated human erythrocytes. Free Radic Biol Med 29: 1122-1128, 2000.

JANNOT MF, RACCAH D, DE LA TOUR DD, COSTE T, VAGUE P: Genetic and environmental regulation of Na/K adenosine triphosphatase activity in diabetic patients. Metabolism 51: 284-291, 2002.

JUBELIN BC, GIERMAN JL: Erythrocytes may synthesize their own nitric oxide. Am J Hypertens 9: 1214-1219, 1996.

JUHAN-VAGUE I, ROUL C, RAHMANI-JOURDHEIL D, MISHAL Z, DRISS F, DURAND-GASSELIN M, AILLAUD MF, VAGUE P: Rapid modifications of biophysical and biochemical parameters of red blood cell membrane from insulin dependent diabetics after insulin administration. Klin Wochenschr 64: 1046-1049, 1986.

KAMENEVA MV, WATACH MJ, BOROVETZ HS: Gender difference in rheologic properties of blood and risk of cardiovascular diseases. Clin Hemorheol Microcirc 21: 357-363, 1999. 
KAZENNOV AM, MASLOVA MN, SHALABODOV AD, BAGROV JYU, GUREVICH VS: Some properties of erythrocyte Na+-K+-ATPase in essential hypertension. Clin Exp Hypertens A 9: 1221-1232, 1987.

KAZENNOV AM, ULIANOVA TP, GANELINA IE, GUSEV GP, KRUCHININA NA, MASLOVA MN: Ionic homeostasis and erythrocyte deformability in patients with primary arterial hypertension. Kardiologiia 30: 19-22, 1990.

KITABCHI AE: The biological and immunological properties of pork and beef insulin, proinsulin, and connecting peptides. J Clin Invest 49: 979-987, 1970.

KOHNO M, MURAKAWA K, YASUNARI K, YOKOKAWA K, HORIO T, KANO H, MINAMI M, YOSHIKAWA $\mathrm{J}$ : Improvement of erythrocyte deformability by cholesterol-lowering therapy with pravastatin in hypercholesterolemic patients. Metabolism 46: 287-291, 1997.

KORBUT R, GRYGLEWSKI RJ: Nitric oxide from polymorphonuclear leukocytes modulates red blood cell deformability in vitro. Eur J Pharmacol 234: 17-22, 1993.

KOTER M, BRONCEL M, CHOJNOWSKA-JEZIERSKA J, KLIKCZYNSKA K, FRANIAK I: The effect of atorvastatin on erythrocyte membranes and serum lipids in patients with type-2 hypercholesterolemia. Eur $J$ Clin Pharmacol 58: 501-506, 2002.

KOTER M, FRANIAK I, BRONCEL M, CHOJNOWSKA-JEZIERSKA J: Effects of simvastatin and pravastatin on peroxidation of erythrocyte plasma membrane lipids in patients with type 2 hypercholesterolemia. Can $J$ Physiol Pharmacol 81: 485-492, 2003.

KOTER M, FRANIAK I, STRYCHALSKA K, BRONCEL M, CHOJNOWSKA-JEZIERSKA J: Damage to the structure of erythrocyte plasma membranes in patients with type-2 hypercholesterolemia. Int J Biochem Cell Biol 36: 205-215, 2004.

KUNT T, SCHNEIDER S, PFÜTZNER A, GOITUM K, ENGELBACH M, SCHAUF B, BEYER J, FORST T: The effect of human proinsulin C-peptide on erythrocyte deformability in patients with Type I diabetes mellitus. Diabetologia 42: 465-471, 1999.

LE DEVEHAT C, KHODABANDEHLOU T, VIMEUX M: Relationship between hemorheological and microcirculatory abnormalities in diabetes mellitus. Diabete Metab 20: 401-404, 1994.

MALFATTI CR, BURGOS LT, RIEGER A, RUDGER CL, TURMINA JA, PEREIRA RA, PAVLAK JL, SILVA LA, OSIECKI R: Decreased erythrocyte $\mathrm{NA}+, \mathrm{K}+$-ATPase activity and increased plasma TBARS in prehypertensive patients. ScientificWorldJournal 2012: 348246, 2012.

MANZELLA D, RAGNO E, ABBATECOLA AM, GRELLA R, PAOLISSO G: Residual C-peptide secretion and endothelial function in patients with Type II diabetes. Clin Sci (Lond) 105: 113-118, 2003.

MARTINEZ M, VAYA A, GIL L, MARTI R, DALMAU J, AZNAR J: The cholesterol/phospholipid ratio of the erythrocyte membrane in children with familial hypercholesterolemia. Its relationship with plasma lipids and red blood cell aggregability. Clin Hemorheol Microcirc 18: 259-263, 1998.

MASUYAMA Y, TSUDA K, SHIMA H, URA M, TAKEDA J, KIMURA K, NISHIO I: Membrane abnormality of erythrocytes is highly dependent on salt intake and renin profile in essential hypertension: an electron spin resonance study. J Hypertens Suppl 6: S266-S268, 1988.

MATURU P, VADDI DR, PANNURU P, NALLANCHAKRAVARTHULA V: Alterations in erythrocyte membrane fluidity and $\mathrm{Na}+/ \mathrm{K}+-\mathrm{ATPase}$ activity in chronic alcoholics. Mol Cell Biochem 339: 35-42, 2010.

MAURYA PK, PRAKASH S: Decreased activity of $\mathrm{Ca}(++)$-ATPase and $\mathrm{Na}(+) / \mathrm{K}(+)$-ATPase during aging in humans. Appl Biochem Biotechnol 170: 131-137, 2013.

MCMILLAN DE: Deterioration of the microcirculation in diabetes. Diabetes 24: 944-957, 1975.

MOKKEN FC, KEDARIA M, HENNY CP, HARDEMAN MR, GELB AW: The clinical importance of erythrocyte deformability, a hemorrheological parameter. Ann Hematol 64: 113-122, 1992.

NAGAI Y, ISHIDA K, HIROOKA M, NISHIMARU K: Effect of ethanol on hemorheology in patients with ischemic cerebrovascular disease and elderly healthy men. Clin Hemorheol Microcirc 25: 135-144, 2001.

NAMAZI G, JAMSHIDI RAD S, ATTAR AM, SARRAFZADEGAN N, SADEGHI M, NADERI G, POURFARZAM M: Increased membrane lipid peroxidation and decreased $\mathrm{Na}+/ \mathrm{K}+$-ATPase activity in erythrocytes of patients with stable coronary artery disease. Coron Artery Dis 26: 239-244, 2015. 
NIGRA AD, MONESTEROLO NE, RIVELLI JF, AMAIDEN MR, CAMPETELLI AN, CASALE CH, SANTANDER VS: Alterations of hemorheological parameters and tubulin content in erythrocytes from diabetic subjects. Int $J$ Biochem Cell Biol 74: 109-120, 2016.

ODASHIRO K, SAITO K, ARITA T, MARUYAMA T, FUJINO T, AKASHI K: Impaired deformability of circulating erythrocytes obtained from nondiabetic hypertensive patients: investigation by a nickel mesh filtration technique. Clin Hypertens 21: 17, 2015.

OTTO C, GEISS HC, LAUBACH E, SCHWANDT P: Effects of direct adsorption of lipoproteins apheresis on lipoproteins, low-density lipoprotein subtypes, and hemorheology in hypercholesterolemic patients with coronary artery disease. Ther Apher 6: 130-135, 2002.

PADMAVATHI P, REDDY VD, KAVITHA G, PARAMAHAMSA M, VARADACHARYULU N: Chronic cigarette smoking alters erythrocyte membrane lipid composition and properties in male human volunteers. Nitric Oxide 23: 181-186, 2010.

PASQUALI, STROCCHI E, MALINI P, CASIMIRRI F, MELCHIONDA N, AMBROSIONI E, LABO G: Heterogeneity of the erythrocyte Na-K pump status in human obesity. Metabolism 34: 802-807, 1985.

PASQUALI R, CESARI MP, MELCHIONDA N, BOSCHI S, MUNARINI A, BARBARA L: Erythrocyte Na-KATPase membrane activity in obese patients fed over a long-term period with a very-low-calorie diet. Metabolism 37: 86-90, 1988.

PENCO M, ROMANO S, DAGIANTI A JR, TOZZI-CIANCARELLI MG, DAGIANTI A: Modifications of whole blood filterability during acute myocardial infarction. Clin Hemorheol Microcirc 22: 153-159, 2000.

PUSL T, BROEDL UC, PARHOFER KG, OTTO C: Long-term LDL apheresis does not stably improve hemorheology in hypercholesterolemic patients with coronary artery disease. Clin Hemorheol Microcirc 41: 137-142, 2009.

PYTEL E, DUCHNOWICZ P, JACKOWSKA P, WOJDAN K, KOTER-MICHALAK M, BRONCEL M: Disorders of erythrocyte structure and function in hypertensive patients. Med Sci Monit 18: BR331-BR336, 2012.

PYTEL E, OLSZEWSKA-BANASZCZYK M, KOTER-MICHALAK M, BRONCEL M: Increased oxidative stress and decreased membrane fluidity in erythrocytes of CAD patients. Biochem Cell Biol 91: 315-318, 2013.

RILLAERTS E, VAN GAAL L, XIANG DZ, VANSANT G, DE LEEUW I: Blood viscosity in human obesity: relation to glucose tolerance and insulin status. Int J Obes 13: 739-745, 1989.

RIVELLI JF, AMAIDEN MR, MONESTEROLO NE, PREVITALI G, SANTANDER VS, FERNANDEZ A, ARCE $\mathrm{CA}, \mathrm{CASALE} \mathrm{CH}$ : High glucose levels induce inhibition of $\mathrm{Na}, \mathrm{K}-\mathrm{ATPase}$ via stimulation of aldose reductase, formation of microtubules and formation of an acetylated tubulin/ $\mathrm{Na}, \mathrm{K}-\mathrm{ATPase}$ complex. Int J Biochem Cell Biol 44: 1203-1213, 2012.

RODRIGO R, MIRANDA-MERCHAK A, VALENZUELA GRAU R, BACHLER JP, VERGARA L: Modulation of $(\mathrm{Na}, \mathrm{K})$-ATPase activity by membrane fatty acid composition: therapeutic implications in human hypertension. Clin Exp Hypertens 36: 17-26, 2014.

SAKLAMAZ A, COMLEKCI A, TEMIZ A, CALISKAN S, CEYLAN C, ALACACIOGLU A, YESIL S: The beneficial effects of lipid-lowering drugs beyond lipid-lowering effects: a comparative study with pravastatin, atorvastatin, and fenofibrate in patients with type IIa and type IIb hyperlipidemia. Metabolism 54: 677-681, 2005.

SCHMID-SCHONBEIN H: Microrheology of erythrocytes, blood viscosity, and the distribution of blood flow in the microcirculation. Int Rev Physiol 9: 1-62, 1976.

SCHMID-SCHONBEIN H, VOLGER E: Red-cell aggregation and red-cell deformability in diabetes. Diabetes 25 : 897-902, 1976.

SOLA E, VAYA A, SANTAOLARIA ML, HERNANDEZ-MIJARES A, REGANON E, VILA V, MARTINEZSALES V, CORELLA D: Erythrocyte deformability in obesity measured by ektacytometric techniques. Clin Hemorheol Microcirc 37: 219-227, 2007.

SOSZYNSKI M, BARTOSZ G: Decrease in accessible thiols as an index of oxidative damage to membrane proteins. Free Radic Biol Med 23: 463-469, 1997. 
SZAPARY L, HORVATH B, MARTON Z, ALEXY T, KESMARKY G, HABON T, SZOTS M, KOLTAI K, JURICSKAY I, CZOPF J, TOTH K: Short-term effect of low-dose atorvastatin on haemorrheological parameters, platelet aggregation and endothelial function in patients with cerebrovascular disease and hyperlipidaemia. CNS Drugs 18: 165-172, 2004.

TOMAIUOLO G: Biomechanical properties of red blood cells in health and disease towards microfluidics. Biomicrofluidics 8: 051501, 2014.

TOTH A, PAPP J, RABAI M, KENYERES P, MARTON Z, KESMARKY G, JURICSKAY I, MEISELMAN HJ, TOTH K: The role of hemorheological factors in cardiovascular medicine. Clin Hemorheol Microcirc 56: 197-204, 2014.

TSUDA K: Adiponectin and membrane fluidity of erythrocytes in normotensive and hypertensive men. Obesity (Silver Spring) 14: 1505-1510, 2006.

TSUDA K: Roles of adiponectin and oxidative stress in the regulation of membrane microviscosity of red blood cells in hypertensive men - an electron spin resonance study. J Obes 2011: 548140, 2011.

TSUDA K, SHIMA H, TAKEDA J, KIMURA K, NISHIO I, MASUYAMA Y: The role of endogenous $\mathrm{Na}^{+}, \mathrm{K}^{+}-$ adenosine triphosphatase inhibitory factor in the regulation of membrane fluidity of erythrocytes in essential hypertension. J Hypertens 10: 657-661, 1992.

TSUDA K, KIMURA K, NISHIO I, MASUYAMA Y: Nitric oxide improves membrane fluidity of erythrocytes in essential hypertension: an electron paramagnetic resonance investigation. Biochem Biophys Res Commun 275: 946-954, 2000.

TSUDA K, KINOSHITA Y, NISHIO I, MASUYAMA Y: Hyperinsulinemia is a determinant of membrane fluidity of erythrocytes in essential hypertension. Am J Hypertens 14: 419-423, 2001.

TSUDA K, KINOSHITA-SHIMAMOTO Y, MABUCHI Y, NISHIO I: Hormone replacement therapy improves membrane fluidity of erythrocytes in postmenopausal women: an electron paramagnetic resonance investigation. Am J Hypertens 16: 502-507, 2003.

VAGUE P, JUHAN I: Red cell deformability, platelet aggregation, and insulin action. Diabetes 32: 88-91, 1983.

VAGUE P, DUFAYET D, COSTE T, MORISCOT C, JANNOT MF, RACCAH D: Association of diabetic neuropathy with Na/K ATPase gene polymorphism. Diabetologia 40: 506-511, 1997.

VAYA A, MARTINEZ M, GUILLEN M, DALMAU J, AZNAR J: Erythrocyte deformability in young familial hypercholesterolemics. Clin Hemorheol Microcirc 19: 43-48, 1998.

WAMBACH G, OVERHOFF U, HOSSMANN V: Sodium transport and red cell deformability. Klin Wochenschr 63: 35-37, 1985.

WATALA C, WITAS H, OLSZOWSKA L, PIASECKI W: The association between erythrocyte internal viscosity, protein non-enzymatic glycosylation and erythrocyte membrane dynamic properties in juvenile diabetes mellitus. Int J Exp Pathol 73: 655-663, 1992.

ZHAO GS, LI DY, ZHU DL, KONG DW, QIAN YW, LI DP: Cellular mechanism relating sodium and potassium to hypertension. Ann Clin Res 16: 55-61, 1984.

ZIOBRO A, DUCHNOWICZ P, MULIK A, KOTER-MICHALAK M, BRONCEL M: Oxidative damages in erythrocytes of patients with metabolic syndrome. Mol Cell Biochem 378: 267-273, 2013. 